\title{
RESEARCH
}

Open Access

\section{The association between the workload of general practitioners and patient experiences with care: results of a cross- sectional study in 33 countries}

Willemijn L. A. Schäfer ${ }^{1 *}$, Michael J. van den Berg ${ }^{2}$ and Peter P. Groenewegen ${ }^{3,4,5^{*}}$ (D)

\begin{abstract}
Background: The workload of general practitioners (GPs) and dissatisfaction with work have been increasing in various Western countries over the past decades. In this study, we evaluate the relation between the workload of GPs and patients' experiences with care.

Methods: We collected data through a cross-sectional survey among 7031 GPs and 67,873 patients in 33 countries. Dependent variables are the patient experiences on doctor-patient communication, accessibility, continuity, and comprehensiveness of care. Independent variables concern the workload measured as the GP-reported work hours per week, average consultation times, job satisfaction (an indicator of subjective workload), and the difference between the workload measures of every GP and the average in their own country. Finally, we evaluated interaction effects between workload measures and what patients find important in a country and the presence of a patient-list system. Relationships were determined through multilevel regression models.

Results: Patients of GPs who are happier with their work were found to experience better communication, continuity, access, and comprehensiveness. When GPs are more satisfied compared to others in their country, patients also experience better quality. When GPs work more hours per week, patients also experience better quality of care, but not in the area of accessibility. A longer consultation time, also when compared to the national average, is only related to more comprehensive care. There are no differences in the relationships between countries with and without a patient list system and in countries where patients find the different quality aspects more important.
\end{abstract}

Conclusions: Patients experience better care when their GP has more work hours, longer consultation times, and especially, a higher job satisfaction.

Keywords: General practice, Workload, Job satisfaction, Patient experiences, International comparison

\footnotetext{
* Correspondence: wilhelmina.schaefer@northwestern.edu;

p.groenewegen@nivel.nl

'Department of Surgery, Feinberg School of Medicine, Northwestern

University, Chicago, IL 60611, USA

${ }^{3} \mathrm{NIVEL}$, the Netherlands Institute for Health Services Research, Utrecht, The Netherlands

Full list of author information is available at the end of the article
}

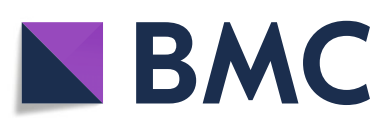

(- The Author(s). 2020 Open Access This article is licensed under a Creative Commons Attribution 4.0 International License, which permits use, sharing, adaptation, distribution and reproduction in any medium or format, as long as you give appropriate credit to the original author(s) and the source, provide a link to the Creative Commons licence, and indicate if changes were made. The images or other third party material in this article are included in the article's Creative Commons licence, unless indicated otherwise in a credit line to the material. If material is not included in the article's Creative Commons licence and your intended use is not permitted by statutory regulation or exceeds the permitted use, you will need to obtain permission directly from the copyright holder. To view a copy of this licence, visit http://creativecommons.org/licenses/by/4.0/. The Creative Commons Public Domain Dedication waiver (http://creativecommons.org/publicdomain/zero/1.0/) applies to the data made available in this article, unless otherwise stated in a credit line to the data. 


\section{Background}

Ageing of populations, changes in lifestyle, and the associated increase of multi-morbidity have led to more and more complex health problems [1-4]. Primary care is increasingly important to address the needs of patients and populations, as is acknowledged both by the World Health Organization [5] and the European Union [6].

The increase in patients with complex health problems changes the work of general practitioners (GPs) and increases their workload. This is for example visible in the increase of the consultation length in the United Kingdom, the United States of America [7], and the Netherlands [8]. Additionally, job satisfaction, a subjective aspect of workload [9], is low and decreasing among primary care physicians in various countries [10-13]. An increased workload has important consequences for patients. When GPs are under time pressure, this may negatively affect the time they have to discuss patients' health problems. This can be a particular problem for patients with complex health problems, including chronic diseases or comorbidities, who may need additional time to have their health issues addressed [14]. Whereas many previous studies focused on the determinants of the workload of GPs (see for example [15-23]), studies on the consequences of high workload in GPs for patient experiences are sparse. Previous studies showed that extended consultation length is related to increased patients' ability to cope with their illness and life in general [24], and more positive experiences with the care provided by GPs [25]. GPs, who more frequently experienced a lack of time, did not differ from other GPs on most communication aspects, except for patient-centredness [26]. More work hours are found to be associated with better perceived availability and accessibility in one study [25] but not in another [27]. Additionally, more work hours are related to more positive patient evaluations on the doctor-patient relationship and medical care and information, but not on accessibility [27].

The current study adds to this literature through studying patients' experiences in four key domains of primary care: accessibility, continuity, and comprehensiveness of care and doctor-patient communication. We study the associations between experiences and three aspects of GP workload: the number of work hours, consultation length, and job satisfaction. The main research question is as follows: What is the relationship between the workload of GPs and patients' experiences of care? Data is used on a large sample of patients and the GPs they consulted in 33 countries in Europe and outside, with a high variation in the workload and patient experiences $[28,29]$. The use of data on a large number of countries allows us to take into account country characteristics in the data analyses.
Longer consultations and a higher job satisfaction are expected to be associated with more positive patient experiences. A higher number of work hours are expected to be associated with more negative experiences, but this can be mitigated by a higher job satisfaction; GPs with more working hours but at the same time a high job satisfaction would be less likely to yield negative patient experiences. The average number of working hours and average consultation time differ between countries. Consequently, the same values may in one country be in the lower end of distribution, but in another country in the higher end. It is therefore important also to look at the deviation from the average within countries. When GPs have shorter work hours, longer consultations, and a higher job satisfaction compared to other GPs in their country, the relation with more positive patient experiences is expected to be stronger. Furthermore, if patients in a country find the experience domain (access, comprehensiveness, continuity, communication), more important, the association with work hours, consultations, and a higher job satisfaction is expected to be more stronger. Finally, we expect that in countries without a patient list system, patients only choose to visit a family physician over another specialist because the family physician better meets their expectations. Therefore, we would expect that the association with the workload variables is stronger in countries where patients are enrolled with a specific GP compared to countries without a list system.

\section{Methods}

\section{Data collection}

Data used in this article were retrieved from the QUALICOPC (Quality and Costs of Primary Care in Europe) study. Within this European Commission-funded study, data were collected among GPs and their patients in 31 European countries (EU 27-except France-, Iceland, Norway, the Republic of Macedonia, Turkey, and Switzerland) between 2011 and 2013. In addition, we used the QUALICOPC data from two non-European countries with health systems comparable to European systems (Canada and New Zealand). In each country, a sample of GPs completed a questionnaire. For most countries, the number of respondents was around 220 GPs. For smaller countries (Cyprus, Iceland, Luxembourg, and Malta), this was around 75 GPs. In most countries, a random sample of GPs was invited to participate. In countries where no national sampling framework was available, alternatives were sought as close as possible to a random sample. Per practice, only one GP participated [30].

In each practice, ten consecutive patients who visited the GP who participated in the study were invited by a fieldworker to complete a questionnaire; nine patients completed a questionnaire about their experiences with 
the consultation they just had, and one patient completed a questionnaire about what $\mathrm{s} / \mathrm{he}$ considers important in the care of GPs. The questions are derived from validated questionnaires. Details of the study design and the development of the questionnaires have been published elsewhere [31, 32]. Ethical review was conducted in accordance with the legal requirements in each country [33].

\section{The dependent variables: patient experiences}

The questionnaire for patients included questions about the perceived accessibility (five questions), continuity (three questions), and comprehensiveness of care (two questions) and doctor-patient communication (three questions). The patients answered the questions with 'yes' or 'no'. Patients were asked, for example, whether the doctor made eye contact during the consultation as an indicator for communication and whether the doctor had their personal medical records at hand as an indicator for continuity of care. The questions were combined in a composite scale score for each of the four areas using multilevel, ecometric analysis $[34,35]$ in which the items are nested in patients, nested in the GP practices, and nested in countries. The resulting scale values (which vary between 0 and 1) are multiplied by 100 for easily interpretable regression coefficients.

\section{Independent variables}

Within this study, objective workload is defined as the amount of time that certain activities consume or the frequency that certain activities take place' [9]. To measure workload, we have selected two indicators that fall within this definition: the regular working hours and average consultation length. GPs reported estimates of the average number of work hours per week, including the regular hours, but excluding evening, night, and weekend shifts. The survey does not distinguish between full-time or part-time working status. To measure consultation length, the GPs were asked to estimate how long a regular patient consultation in their office usually takes (in minutes).

Job satisfaction, representing subjective workload of GPs, was measured using a scale score on six items derived from the European Task Profile Study [36]. The items are:

- I feel that some parts of my work do not really make sense.

- My work still interests me as much as it ever did.

- My work is overloaded with unnecessary administrative detail.

- I have too much stress in my current job.

- Being a general practitioner is a well-respected job.
- In my work, there is a good balance between effort and reward.

For each item, the GPs indicated to what extent they agreed on a scale of 1 (strongly disagree) to 4 (strongly agree). The items were coded so that a higher score indicates higher satisfaction. We constructed a scale using ecometric analysis, in which items are nested in GPs and nested in countries.

We calculated the deviation from the national average, by subtracting the national average from the individual values of each GP. In addition, we calculated the average importance that patients attach to the four aspects of the quality of GP care. Country-level scales for each domain were constructed using latent multilevel regression analyses. In the models, we adjusted for the age, gender, level of household income, ethnicity, and level of education of the patients [37].

\section{Confounders}

We included the GP characteristics, age (centred) and sex. At the patient level, we included several sociodemographic variables: age (centred), sex, perceived health (poor, fair, good, very good), the presence of one or more chronic diseases (yes or no), ethnicity (first-generation, second-generation immigrant, native), education (low, medium, high), and income (below average, average, above average). Sociodemographic variables are related to patient experiences $[38,39]$.

\section{Statistical analysis}

Within this study, we focus on the independent association between the three workload variables and the experiences of patient. To determine the associations, we have performed multi-level linear regression with three levels: country, GP, and patient. Consequently, variation in patient experiences is at three levels, and we have calculated the intraclass correlations (ICC) at GP and country level, as the percentage of total variation residing at that level. The analyses were done for each of the four patient experience outcome variables using a stepwise approach with 11 steps. In the first step, an empty model was estimated to show how the patient experiences are clustered on different levels. In the second model, we added the confounders. In the third model, we added the indicators for workload. In the fourth model we added the interaction term for satisfaction and work hours. In the fifth model, we analysed the individual deviations on the workload variables from the averages instead of the absolute values of the workload variables (confounders in the model). In models 6 to 8 , we returned to model 4 and added one by one the interactions between the importance that the patients in each country attached to the accessibility, communication, 
comprehensiveness, and continuity of care and the three workload indicators. In models 9 to 11, we analysed the interactions between the presence of a list system and the three workload indicators (added to model 4). The complete 11step model results are in Additional file 1: Appendix Tables 2-5. We used the software programme Stata (version 14.2).

\section{Results}

The total number of participating GPs amounts to 7031 . In total, 60,741 patients completed the questionnaire on experiences, and 7132 patients about what they find important.

\section{Variation in patient experiences}

The average values for the patient experiences on accessibility range from 64.5 in Cyprus to 93.7 in New Zealand, for communication from 91.9 in Italy to 99.1 in Canada, for comprehensiveness from 41.0 in Cyprus to 83.9 in Portugal, and for continuity from 57.4 in Cyprus to 99.0 in New Zealand (see Fig. 1 and Additional file 1: Appendix Table 1). The experience of the physicianpatient communication mostly varies between patients (more than half of the variation), but there is also substantial variation between GPs (36\% of the variation) and between countries (12\% of the variation). The variation in the perceived continuity of care is more than one third at the patient level, more than one third at the country level, and about a quarter at the level of GPs. The distribution of the variation in experience of the accessibility and comprehensiveness of care is completely different: there is hardly any variation between patients (respectively 4 and 2\%), but especially among GPs (respectively 55 and 53\%) and countries (respectively 41 and 45\%) (see Additional file 1: Appendix Tables 2-5).

\section{Workload and job satisfaction of GPs}

The average number of hours worked varies from $33.5 \mathrm{~h}$ in Italy to $51.1 \mathrm{~h}$ per week in Belgium. The average consultation time varies from about $8 \mathrm{~min}$ in Hungary to $24 \mathrm{~min}$ in Finland and Sweden (see Table 1). GPs in Denmark are most satisfied with their job, whereas the Spanish and Hungarian GPs reported on average the lowest job satisfaction.

\section{The relationship between patient experiences and GP workload}

Table 2 provides a summary of the analyses on the relation between workload and patient experiences. Additional file 1: Appendix Tables $2-5$ provide the detailed outcomes of all models, including numbers of observations for all levels, all regression coefficients, variances for all levels, and intraclass correlations. The patients of GPs who work more hours per week experience better communication, continuity, and comprehensiveness of care. For GPs with a longer working week compared to the average in their country, patient experiences on continuity and comprehensiveness are also more positive. The relation between patient perceived continuity and work hours is also stronger when the GPs are more satisfied. A longer consultation time is only related to better

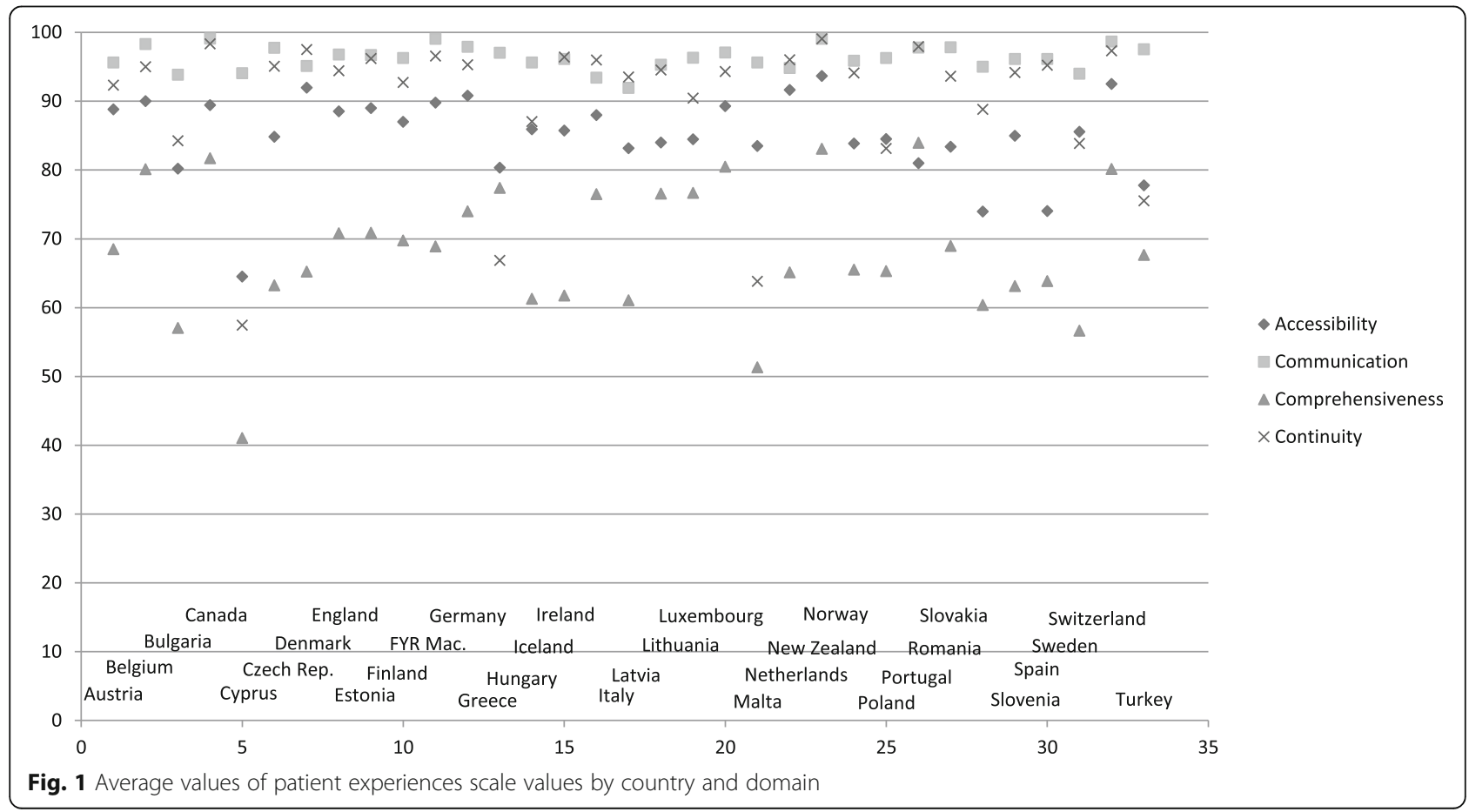


Table 1 Average number of work hours, duration of consultations, and job satisfaction score of GPs in 33 countries (standard deviation)

\begin{tabular}{|c|c|c|c|c|}
\hline & GPs in QUALICOPC database $(n)$ & Work hours per week & Duration of consultations in minutes & Job satisfaction score \\
\hline Austria & 184 & $43.7(12.5)$ & $11.7(12.4)$ & $2.44(.30)$ \\
\hline Belgium & 408 & $51.1(13.1)$ & $17.7(5.9)$ & $2.59(.27)$ \\
\hline Bulgaria & 223 & $39.2(13.5)$ & $17.6(6.0)$ & $2.44(.28)$ \\
\hline Canada & 792 & $40.4(11.8)$ & $14.8(9.2)$ & $2.77(.30)$ \\
\hline Cyprus & 71 & $37.5(5.8)$ & $18.3(9.0)$ & $2.81(.21)$ \\
\hline Czech Republic & 291 & $36.2(8.9)$ & $10.9(4.8)$ & $2.49(.23)$ \\
\hline Denmark & 212 & $40.9(7.3)$ & $14.3(2.1)$ & $2.97(.27)$ \\
\hline England & 171 & $40.1(10.5)$ & $11.2(2.1)$ & $2.49(.32)$ \\
\hline Estonia & 137 & $37.8(10.0)$ & $16.4(3.8)$ & $2.27(.23)$ \\
\hline Finland & 288 & $35.8(7.6)$ & $23.8(6.3)$ & $2.59(.30)$ \\
\hline FYR Macedonia & 143 & $40.8(3.1)$ & $13.4(4.8)$ & $2.35(.26)$ \\
\hline Germany & 238 & $49.6(9.7)$ & $10.6(4.0)$ & $2.45(.28)$ \\
\hline Greece & 220 & $38.2(11.2)$ & $14.7(6.3)$ & $2.62(.28)$ \\
\hline Hungary & 222 & $37.7(8.6)$ & $8.2(5.5)$ & $2.17(.31)$ \\
\hline Iceland & 80 & $39.8(7.0)$ & $19.2(2.7)$ & $2.50(.28)$ \\
\hline Ireland & 169 & $41.2(10.4)$ & $12.8(3.3)$ & $2.60(.28)$ \\
\hline Italy & 218 & 33.5 (12.9) & $13.4(4.0)$ & $2.37(.30)$ \\
\hline Latvia & 218 & $38.9(9.8)$ & $17.5(6.6)$ & $2.36(.23)$ \\
\hline Lithuania & 225 & $35.2(9.3)$ & $15.9(4.2)$ & $2.27(.27)$ \\
\hline Luxembourg & 78 & $45.6(11.9)$ & $17.6(5.0)$ & $2.71(.23)$ \\
\hline Malta & 70 & $46.3(13.2)$ & $13.0(4.2)$ & $2.47(.35)$ \\
\hline Netherlands & 238 & $43.0(10.0)$ & $11.1(1.7)$ & $2.63(.25)$ \\
\hline New Zealand & 168 & $36.8(10.5)$ & $14.9(3.9)$ & $2.68(.31)$ \\
\hline Norway & 198 & $36.1(10.1)$ & $18.6(2.8)$ & $2.75(.27)$ \\
\hline Poland & 220 & $38.4(7.6)$ & $13.7(5.1)$ & $2.41(.27)$ \\
\hline Portugal & 216 & $40.2(4.5)$ & $18.1(6.6)$ & $2.41(.25)$ \\
\hline Romania & 220 & $35.8(8.0)$ & $16.6(5.1)$ & $2.38(.28)$ \\
\hline Slovakia & 220 & $37.4(8.7)$ & $8.9(3.5)$ & $2.23(.31)$ \\
\hline Slovenia & 207 & $37.4(6.6)$ & $9.6(3.1)$ & $2.29(.27)$ \\
\hline Spain & 428 & $35.8(4.3)$ & $8.5(4.5)$ & $2.15(.28)$ \\
\hline Sweden & 97 & $34.4(9.7)$ & $23.9(5.5)$ & $2.73(.30)$ \\
\hline Switzerland & 199 & 46.5 (11.6) & $19.5(5.8)$ & $2.70(.28)$ \\
\hline Turkey & 299 & $40.8(4.1)$ & $9.3(5.6)$ & $2.30(.28)$ \\
\hline
\end{tabular}

comprehensiveness, and this is also true for GPs with longer consultations than the national average. Patients of GPs who are more satisfied with their work have more positive experiences with communication, accessibility, continuity, and comprehensiveness of care. These relationships are also found for physicians with a higher job satisfaction compared to others in their country. After adding all workload variables to the model, we found small reductions in the variances of up to $2.8 \%$ for accessibility at the country level (Additional file 1: Appendix Tables 2-5, percentages of change not indicated in table).
We did not find differences in the relation between workload and patient experiences between countries with and without a patient list system and in countries where patients find communication, continuity, accessibility, and comprehensiveness more important.

\section{Discussion}

The shortest summary of our findings is that there is a positive association between GP job satisfaction and patient-reported experiences of care. This finding concerns all four measured areas of patient experiences. In 
Table 2 Summary multilevel regression coefficients (with 95\% C.I.) of aspects of workload and job satisfaction of GPs and patient experiences (for complete models, see Additional file 1: Appendix Tables 2-5)

\begin{tabular}{|c|c|c|c|c|}
\hline & Communication & Continuity & Accessibility & Comprehensiveness \\
\hline \multicolumn{5}{|l|}{ Model 3: Workload variables (main effects) } \\
\hline Work hours per week (average) & $0.01(0.00-0.02)^{*}$ & $0.05(0.03-0.08)^{* *}$ & $0.02(-0.00$ to 0.04$)$ & $0.04(0.01-0.07)^{* *}$ \\
\hline Consultation time (minutes) & $-0.002(-0.02$ to 0.01$)$ & $0.02(-0.03$ to 0.06$)$ & $-0.01(-0.04$ to 0.03$)$ & $0.11(0.06-0.16)^{* *}$ \\
\hline Job satisfaction (scales $1-4$ ) & $0.55(0.27-0.82)^{* *}$ & $1.44(0.63-2.26)^{* *}$ & $1.19(0.58-1.80)^{* *}$ & $1.76(0.81-2.72)^{* *}$ \\
\hline \multicolumn{5}{|c|}{ Model 4: Interaction between job satisfaction and work hours } \\
\hline Work hours $\times$ job satisfaction & $-0.02(-0.04$ to 0.01$)$ & $0.04(-0.03$ to 0.10$)$ & $-0.02(-0.07$ to 0.03$)$ & $0.01(-0.06$ to 0.09$)$ \\
\hline \multicolumn{5}{|l|}{ Model 5: Deviation from national averages } \\
\hline Deviation national average work hours & $0.01(-0.00$ to 0.02$)$ & $0.05(0.03-0.08)^{* *}$ & $0.02(-0.00$ to 0.03$)$ & $0.04(0.01-0.07)^{* *}$ \\
\hline Deviation national average cons. time & $-0.002(-0.02$ to 0.01$)$ & $0.02(-0.03$ to 0.06$)$ & $-0.01(-0.04$ to 0.03$)$ & $0.11(0.06-0.16)^{* *}$ \\
\hline Deviation national average job satisfaction & $0.55(0.27-0.82)^{* *}$ & $1.45(0.64-2.27)^{* *}$ & $1.17(0.56-1.78)^{* *}$ & $1.76(0.80-2.71)^{* *}$ \\
\hline \multicolumn{5}{|c|}{ Models 6-8: Interactions between patient values and workload } \\
\hline Values $\times$ work hours & $0.04(-0.03$ to 0.11$)$ & $-0.06(-0.21$ to 0.10$)$ & $0.06(-0.13$ to 0.25$)$ & $-0.06(-0.17$ to 0.05$)$ \\
\hline Values $\times$ consultation time & $0.12(-0.00$ to 0.24$)$ & $0.19(-0.07$ to 0.45$)$ & $0.07(-0.04$ to 0.17$)$ & $0.09(-0.13$ to 0.31$)$ \\
\hline Values $\times$ job satisfaction & $0.12(-2.15$ to 2.39$)$ & $-0.45(-5.41$ to 4.51$)$ & $2.67(-0.73$ to 6.07$)$ & $-2.22(-6.21$ to 1.77$)$ \\
\hline \multicolumn{5}{|c|}{ Models 9-11: Interactions between patient list system and workload } \\
\hline Patient list system $\times$ work hours & $-0.002(-0.02$ to 0.02$)$ & $-0.01(-0.06$ to 0.05$)$ & $0.004(-0.04$ to 0.04$)$ & $0.01(-0.05$ to 0.07$)$ \\
\hline Patient list system $\times$ consultation time & $-0.01(-0.04$ to 0.03$)$ & $-0.09(-0.19$ to 0.01$)$ & $-0.01(-0.08$ to 0.06$)$ & $-0.10(-0.21$ to 0.01$)$ \\
\hline Patient list system $\times$ job satisfaction & $0.16(-0.50$ to 0.82$)$ & $-1.93(-3.86$ to 0.001$)$ & $0.51(-0.92$ to 0.95$)$ & $-1.46(-3.70$ to 0.78$)$ \\
\hline
\end{tabular}

addition, we found positive associations between the average work hours and the patient perceived communication, continuity, and comprehensiveness of care. It is likely that GPs, who work more hours, are more often available for consultations and therefore know their patients and their medical backgrounds better (continuity), take more time to ask about various aspects of the patients' health (comprehensiveness), and pay more attention to their communication.

\section{Main findings compared to other studies}

A study in the United Kingdom [40] did not find an association between consultation length and patient experiences in the areas of communication, trust and confidence, and overall satisfaction. We only found an association of consultation length with experienced comprehensiveness of care, but also not with communication.

Previous studies found that more work hours are related to a broader availability of people's 'own' GP [25, 27]. This is important against the background of the increasing numbers of female GPs who tend to work less hours [41]; in general, part-time working is on the increase among GPs. We did find that patients of GPs with more work hours experience more comprehensiveness, measured as their doctor discussing multiple problems, including personal problems. One study found no relationship between the workload of GPs and their awareness of psychological problems [26], but another study found indications that longer consultations led to a better diagnosis of psychological problems [42].

In addition to the experiences of patients, it is also important to consider the associations between workload and clinical quality of care. Other studies found that GPs under time pressure provided reduced quality of care during physical examination [43] and a less thorough clinical examination and gave less advice on lifestyle [44]. A positive relation between the workload of GPs and cardiovascular prevention was found [45]. No relation was found between GP workload and adherence to guidelines [46].

\section{Limitations and strengths}

This study has some limitations. Firstly, the data on workload are based on self-reports from GPs and not on actual time measurements. Hence, the actual number of hours worked or the consultation length might differ from the reported figures. The number of work hours could be underestimated by GPs, as was observed in the Netherlands [47]. However, we expect that this does not affect the comparisons between countries. Secondly, the recruitment and participation of GPs in the study differs between countries, even though we attempted to implement the study as uniform as possible. GPs who feel 
overloaded may have decided not to participate. Thirdly, only patients who visited their GP completed the patient questionnaire. Patients without access to their GP were not reached. Another potential limitation is that the patient experience scales were developed from previously validated survey questions and scales. However, some questions were adapted and not validated in their current form. Finally, the associations presented in this analysis are based on cross-sectional data. Therefore, causal interpretation is not warranted.

The study has several strengths. We use comparable data on many countries with large numbers of GPs and patients. The response groups are largely representative for the GP population by gender and average age [30]. A limitation, but at the same time a strength, is that this study only evaluated the experiences of patients with their GPs. This is a strength because it makes the direct link between GP questionnaires and the questionnaires of their patient possible. A limitation is that in modern primary care practices, care is also provided by other professionals, such as practice nurses. Future research on the relationship between workload and patient experiences should therefore also look at the experiences of patients with other staff in primary care in relation to their workload.

\section{Implications for policy, practice, or research}

The results of this study show that job satisfaction does not only relate to physician burnout and clinical quality of care, but also to patient experiences. GP job satisfaction varies between countries, with Spanish, Hungarian, Slovakian, Estonian, and Latvian doctors being least satisfied. Potential determinants of the job satisfaction of GPs include the electronic medical records system [23], the way out-of-hours service delivery is organized [4851], the payment system [52], the practice location [53], and the workload of GPs. Results of studies on the workload and the job satisfaction of GPs are, however, ambiguous. A number of studies found no relation between workload and satisfaction $[54,55]$ or subjective workload [23]. On the other hand, another study found that higher workload resulted in lower satisfaction with work [44]. A longer consultation is associated with less stress from the GP $[24,56]$.

In addition, the work hours are associated with the experiences of the patients. Countries with the lowest average work hours include Italy, Sweden, Lithuania, Romania, and Finland. In further studies, the impact of continuous availability of the same GP needs to be studied. This may be particularly relevant for patients with complex diseases such as cancer or diabetes. Finally, longer consultation times, more work hours, and job satisfaction were all related to the patient-perceived comprehensiveness. The option to discuss multiple problems during consultations is especially important for patients with multimorbidity. Globally, there are large differences in consultation times [7].

\section{Conclusion}

The subjective and objective workload of GPs is related to the experiences of patients. We found that GPs provide a better patient experience when they work longer hours, have longer consultation times, and have high levels of job satisfaction.

\section{Supplementary information}

Supplementary information accompanies this paper at https://doi.org/10. 1186/s12960-020-00520-9.

Additional file 1:. Appendix Tables

\section{Abbreviations}

FYR Macedonia: Former Yugoslav Republic of Macedonia; GP(s): General practitioner(s); ICC: Intraclass correlation; QUALICOPC: Quality and Costs of Primary Care in Europe

\section{Acknowledgements}

The authors thank their partners in the QUALICOPC project: J De Maeseneer, J Detollenaere, L Hanssens, and S Willems (Belgium); S Greß and S Heinemann (Germany); G Capitani, S De Rosis, AM Murante, S Nuti, C Seghieri, and M Vainieri (Italy); D Kringos and T Van Loenen (the Netherlands); and D Rotar Pavlič and I Švab (Slovenia). The authors thank the coordinators of the data collection in each country: $L$ Jorm and I McRae (Australia); K Hoffmann and M Maier (Austria); P Salchev (Bulgaria); W Wodchis and W Hogg (Canada); G Samoutis (Cyprus); B Seifert and N Šrámková (Czech Republic); J Reinholdt Jensen and P Vedsted (Denmark); M Lember and K Põlluste (Estonia); E Kosunen (Finland); C Lionis (Greece); I Rurik (Hungary); J Heimisdóttir and O Thorgeirsson (Iceland); C Collins (Ireland); G Ticmane (Latvia); S Macinskas (Lithuania); M Aubart, J Leners, and $\mathrm{R}$ Stein (Luxembourg); G Bezzina and P Sciortino (Malta); T Ashton and R McNeill (New Zealand); T Bjerve Eide and H Melbye (Norway); M Oleszczyk and A Windak (Poland); L Pisco (Portugal); D Farcasanu (Romania); E Jurgova (Slovakia); T Dedeu (Spain); C Björkelund and T Faresjö (Sweden); T Bisschoff and N Senn (Switzerland); K Stavric (The former Yugoslav Republic of Macedonia); M Akman (Turkey); and C Sirdifield and N Siriwardena (United Kingdom).

\section{Authors' contributions}

WS designed the study, did the statistical analysis, and wrote the first draft. MvdB commented on the design, the statistical analysis, and drafts. PG commented on the design, the statistical analysis, and drafts. All authors read and approved the final manuscript.

\section{Funding}

This article is based on data from the QUALICOPC (Quality and Costs of Primary Care in Europe) project, co-funded by the European Commission under the Seventh Framework Programme (FP7/2007-2013) under grant agreement 242141 . The analysis, reported in this article, was not separately funded. The responsibility for the information and the views set out in this paper lie entirely with the authors.

\section{Availability of data and materials}

The datasets used and/or analysed during the current study are available from the corresponding author on reasonable request.

Ethics approval and consent to participate

Ethical approval for the QUALICOPC study was acquired in accordance with the legal requirements in each country [33]. 


\section{Consent for publication}

Not applicable.

\section{Competing interests}

The authors declare that they have no competing interests.

\section{Author details}

'Department of Surgery, Feinberg School of Medicine, Northwestern University, Chicago, IL 60611, USA. ²Department of Public Health, Academic Medical Center, Amsterdam, the Netherlands. ${ }^{3}$ NIVEL, the Netherlands Institute for Health Services Research, Utrecht, The Netherlands. ${ }^{4}$ Department of Human Geography, Utrecht University, Utrecht, The Netherlands. ${ }^{5}$ Department of Sociology, Utrecht University, Utrecht, The Netherlands.

\section{Received: 17 July 2020 Accepted: 2 October 2020}

\section{Published online: 16 October 2020}

\section{References}

1. van Oostrom SH, Gijsen R, Stirbu I, Korevaar JC, Schellevis FG, Picavet HS, et al. Time trends in prevalence of chronic diseases and multimorbidity not only due to aging: data from general practices and health surveys. PLoS One. 2016;11(8):e0160264.

2. Remington PL, Brownson RC. Centers for disease C, prevention. Fifty years of progress in chronic disease epidemiology and control. MMWR Suppl. 2011:60(4):70-7.

3. Busse R, Blümel M, Scheller-Kreinsen D, Zentner A. Tackling chronic diseases in Europe: strategies, interventions and challenges. United Kingdom: World Health Organization on behalf of the European Observatory on Health Systems and Policies; 2010

4. World Health Organization. Global status report on noncommunicable diseases 2010. World Health Organization, 2011.

5. World Health Organization. The World Health Report 2008: primary health care - now more than ever. Geneva 2008.

6. European Commission EXpert Panel on effective ways of investing in health Definition of a frame of reference in relation to primary care with a special emphasis on financing systems and referral systems. Brussels: European Commission: DG Health \& Copnsumers; 2014.

7. Irving G, Neves AL, Dambha-Miller H, Oishi A, Tagashira H, Verho A, et al. International variations in primary care physician consultation time: a systematic review of 67 countries. BMJ Open. 2017;7(10):e017902.

8. Flinterman LKJ, de Bakker D. Zorggebruik in de huisartspraktijk : impact van beleidsmaatregelen op het zorggebruik van oudere patiënten [health care utilization in family physician practices: impact of policy measures on the health care utilization of elderly patients]. Utrecht: NIVEL; 2016.

9. Groenewegen PP, Hutten JBF. Workload and job satisfaction among general practitioners: a review of the literature. Soc Sci Med. 1991;32(10):1111-9.

10. Shanafelt TD, Hasan O, Dyrbye LN, Sinsky C, Satele D, Sloan J, et al. Changes in burnout and satisfaction with work-life balance in physicians and the general US working population between 2011 and 2014. Mayo Clin Proc. 2015;90(12):1600-13

11. Gibson J, Checkland K, Coleman A, Hann M, McCall R, Spooner S, et al. Eighth national GP Worklife survey. Machester, U.K.: PRUComm; 2015.

12. Kairys J, Zebiene E, Sapoka V, Zokas I. Satisfaction with organizational aspects of health care provision among Lithuanian physicians. Cent Eur J Public Health. 2008;16(1):29-33

13. Behmann $M$, Schmiemann $G$, Lingner $H$, Kuhne F, Hummers-Pradier $E$, Schneider N. Job satisfaction among primary care physicians: results of a survey. Dtsch Arztebl Int. 2012;109(11):193-200.

14. Ostbye T, Yarnall KS, Krause KM, Pollak Kl, Gradison M, Michener JL. Is there time for management of patients with chronic diseases in primary care? Ann Fam Med. 2005;3(3):209-14.

15. Beasley JW, Karsh BT, Hagenauer ME, Marchand L, Sainfort F. Quality of work life of independent vs employed family physicians in Wisconsin: a WReN study. Ann Fam Med. 2005;3(6):500-6.

16. Laurant MGH, Hermens RPMG, Braspenning JCC, Sibbald B, Grol RPTM Impact of nurse practitioners on workload of general practitioners: randomised controlled trial. British Med J. 2004:328(7445):927-30.

17. Merilind E, Vǒstra K, Salupere R, Kolde A, Kalda R. The impact of pay-forperformance on the workload of family practices in Estonia. Quality Primary Care. 2014;22(2):109-14.
18. Salisbury C, Montgomery AA, Simons L, Sampson F, Edwards S, Baxter H, et al. Impact of advanced access on access, workload, and continuity: controlled before-and-after and simulated-patient study. British J Gen Practice. 2007:57(541):608-14.

19. Šter MP, Švab I, Kalan GŽ. Factors related to consultation time: experience in Slovenia. Scand J Primary Health Care. 2008;26(1):29-34.

20. Wilson AD, Childs S, Goncalves-Bradley DC, Irving GJ. Interventions to increase or decrease the length of primary care physicians' consultation. Cochrane Database Syst Rev. 2016;8:CD003540.

21. Zantinge EM, Verhaak PFM, De Bakker DH, Van Der Meer K, Bensing JM. Does the attention general practitioners pay to their patients' mental health problems add to their workload? A cross sectional national survey. BMC Fam Pract. 2006:7.

22. Sarma S, Hajizadeh M, Thind A, Chan R. The association between health information technology adoption and family physicians' practice patterns in Canada: evidence from 2007 and 2010 national physician surveys Healthcare Policy. 2013:9(1):89.

23. Babbott S, Manwell LB, Brown R, Montague E, Williams E, Schwartz M, et al. Electronic medical records and physician stress in primary care: results from the MEMO study. J Am Med Inform Assoc. 2014;21(E2): e100-e6.

24. Mercer SW, Fitzpatrick B, Gourlay G, Vojt G, McConnachie A, Watt GCM. More time for complex consultations in a high-deprivation practice is associated with increased patient enablement. Br J Gen Pract. 2007;57(545): 960-6.

25. Van Den Hombergh P, Künzi B, Elwyn G, Van Doremalen J, Akkermans R, Grol R, et al. High workload and job stress are associated with lower practice performance in general practice: an observational study in 239 general practices in the Netherlands. BMC Health Services Res. 2009;9.

26. Zantinge EM, Verhaak PFM, de Bakker DH, Kerssens JJ, van der Meer K, Bensing JM. The workload of general practitioners does not affect their awareness of patients' psychological problems. Patient Educ Couns. 2007; 67(1-2):93-9.

27. Heje HN, Vedsted P, Sokolowski I, Olesen F. Doctor and practice characteristics associated with differences in patient evaluations of general practice. BMC Health Serv Res. 2007;7.

28. Schafer WLA, Boerma WGW, Murante AM, Sixma HJM, Schellevis FG, Groenewegen PP. Assessing the potential for improvement of primary care in 34 countries: a cross-sectional survey. WHO Bulletin. 2015.

29. Schäfer WLA, Van den Berg MJ, PP G. De werkbelasting van huisartsen in internationaal perspectief [the workload of GPs in international perspective]. Huisarts en Wetenschap. 2016:59(3):94-101.

30. Groenewegen PP, Gre S, Schäfer W. General practitioners' participation in a large, multi-country combined general practitioner - patient survey: recruitment procedures and participation rate. International Journal of Family Medicine. 2016;2016:1-9.

31. Schäfer WL, Boerma WG, Kringos DS, De Maeseneer J, Gress S, Heinemann S, et al. QUALICOPC, a multi-country study evaluating quality, costs and equity in primary care. BMC Fam Pract. 2011:12:115.

32. Schäfer WL, Boerma WG, Kringos DS, De Ryck E, Greß S, Heinemann S, et al. Measures of quality, costs and equity in primary care instruments developed to analyse and compare primary care in 35 countries. Qual Prim Care. 2013:21(2):67-79.

33. Pavlic DR, Sever M, Klemenc-Ketis Z, Svab I. Process quality indicators in family medicine: results of an international comparison. BMC Fam Pract. 2015;16(1):172.

34. Raudenbush S. The quantitative assessment of neighborhood social environments. In: Kawachi I BL, editor. Neighborhoods and Health: Oxford Press; 2003.

35. Leyland AH, Groenewegen PP. Multilevel modelling for public health and health services research: health in context. SpringerOpen. 2020.

36. Boerma WG, van der Zee J, Fleming DM. Service profiles of general practitioners in Europe. European GP task profile study. Br J Gen Pract. 1997; 47(421):481-6.

37. Schäfer WLA, Boerma WGW, Schellevis FG, PP G. GP practices as a one stop shop: how do patients perceive the quality of care? Accepted for publication by Health Services Research. 2018

38. Damman OC, Stubbe JH, Hendriks M, Arah OA, Spreeuwenberg P, Delnoij DM, et al. Using multilevel modeling to assess case-mix adjusters in consumer experience surveys in health care. Med Care. 2009;47(4):496-503. 
39. de Boer D, van der Hoek L, Rademakers J, Delnoij D, van den Berg M. Do effects of common case-mix adjusters on patient experiences vary across patient groups? BMC Health Serv Res. 2017;17(1):768.

40. Elmore N, Burt J, Abel G, Maratos FA, Montaque J, Campbell J, et al. Investigating the relationship between consultation length and patient experience: a cross-sectional study in primary care. Br J Gen Pract. 2016. https://doi.org/10.3399/bjgp16X687733.

41. Hedden L, Barer ML, Cardiff K, McGrail KM, Law MR, Bourgeault IL. The implications of the feminization of the primary care physician workforce on service supply: a systematic review. Human Res Health. 2014;12:32.

42. Hutton C, Gunn J. Do longer consultations improve the management of psychological problems in general practice? A systematic literature review. BMC Health Serv Res. 2007;7.

43. Linzer M, Manwell LB, Williams ES, Bobula JA, Brown RL, Varkey AB, et al. Working conditions in primary care: physician reactions and care quality. Annals Internal Med. 2009;151(1):28-36.

44. Tsiga E, Panagopoulou E, Sevdalis N, Montgomery A, Benos A. The influence of time pressure on adherence to guidelines in primary care: an experimental study. BMJ Open. 2013;3(4).

45. Pelletier-Fleury N, Le Vaillant M, Hebbrecht G, Boisnault P. Determinants of preventive services in general practice. A multilevel approach in cardiovascular domain and vaccination in France. Health Policy. 2007;81 (23):218-27.

46. Van Den Berg MJ, De Bakker DH, Spreeuwenberg P, Westert GP, Braspenning JC, Van Der Zee J, et al. Labour intensity of guidelines may have a greater effect on adherence than GPs' workload. BMC Fam Pract. 2009;10.

47. van Hassel D, van de Velden L, Batenburg R. Landelijk SMStijdsbestedingsonderzoek huisartsen [Dutch national SMS study on time allocation of family physicians]. Utrecht: NIVEL; 2014.

48. Giesen P, Smits M, Huibers L, Grol R, Wensing M. Quality of after-hours primary care in the Netherlands: a narrative review. Ann Intern Med. 2011; 155(2):108-13.

49. Smits M, Keizer E, Huibers L, Giesen P. GPs' experiences with out-of-hours GP cooperatives: a survey study from the Netherlands. European Journal of General Practice. 2014;20(3):196-201.

50. Huber CA, Rosemann T, Zoller M, Eichler K, Senn O. Out-of-hours demand in primary care: frequency, mode of contact and reasons for encounter in Switzerland. J Eval Clin Pract. 2011:17(1):174-9.

51. Huibers L, Giesen P, Wensing M, Grol R. Out-of-hours care in western countries: assessment of different organizational models. BMC Health Serv Res. 2009;9.

52. Whalley D, Gravelle H, Sibbald B. Effect of the new contract on GPs' working lives and perceptions of quality of care: a longitudinal survey. $\mathrm{Br} J$ Gen Pract. 2008;58(546):8-14.

53. McGrail MR, Humphreys JS, Scott A, Joyce CM, Kalb G. Professional satisfaction in general practice: does it vary by size of community? Med J Aust. 2010;193(2):94-8.

54. Granja M, Ponte C, Cavadas LF. What keeps family physicians busy in Portugal? A multicentre observational study of work other than direct patient contacts. BMJ Open. 2014;4(6).

55. Karsh BT, Beasley JW, Brown RL. Employed family physician satisfaction and commitment to their practice, work group, and health care organization Health Serv Res. 2010;45(2):457-75.

56. Vanagas $\mathrm{G}$, Bihari-Axelsson $\mathrm{S}$. The factors associated to psychosocial stress among general practitioners in Lithuania. Cross-sectional study. BMC Health Serv Res. 2005;5:45.

\section{Publisher's Note}

Springer Nature remains neutral with regard to jurisdictional claims in published maps and institutional affiliations.

Ready to submit your research? Choose BMC and benefit from:

- fast, convenient online submission

- thorough peer review by experienced researchers in your field

- rapid publication on acceptance

- support for research data, including large and complex data types

- gold Open Access which fosters wider collaboration and increased citations

- maximum visibility for your research: over $100 \mathrm{M}$ website views per year

At BMC, research is always in progress.

Learn more biomedcentral.com/submissions 